\title{
Time Consumable SARS Cov-2 Testing With RT- PCR in Indonesia: A Survey Study
}

\author{
Ade Heryana ${ }^{1 *}$ Erlina Puspitaloka Mahadewi ${ }^{1}$ \\ ${ }^{1}$ Department of Public Health, Faculty of Health Sciences Universitas Esa Unggul \\ Corresponding author: heryana@esaunggul.ac.id
}

\begin{abstract}
The requirement of Severe Acute Respiratory Syndrome Corona Virus-2 (SARS CoV-2) testing particularly with Polymerase Chain Reaction (RT-PCR) technology grow-up in line with the enhancement of Covid-19 pandemic. RTPCR made a pivotal role in SARS-CoV-2 testing, although it is not suitable for high density people and scarcity of resources like Indonesia. This study aims to investigating and capturing the patient's complaint related to the backward of RT-PCR i.e. time consumable compare to point-of-care (POC) test.

Method: A cross-sectional online survey study had been executed to 174 Indonesia participants in August 2020. The 112 participants involved in this study after exclusion criteria and data cleaning. We investigated the patient's experience of SARS-CoV-2 testing from registration, specimen sampling, and receive the results. Collected data were analyzed with proportion descriptive analytics to capturing the time-related attribute of testing.

Result: Participants in this study were $43.2 \%$ less than 31 years old, $43.9 \%$ examined at government hospitals, and $73.5 \%$ stay in Greater Jakarta. A 50\% of participants stated satisfied to the whole RT-PCR from registration to results, $51.5 \%$ satisfy to registration process, and $57.6 \%$ satisfy to the specimen sampling process. Even though a half of participants had satisficing experience in RT-PCR, time-related service attributes under performance i.e. registration service time exceed to 5 minutes (30\%), swab sampling 1-3 minutes (49.2\%), and registration to result received exceed to 3 days (47\%). Based on study result, this paper discusses particularly on the lack of time-related services attributes that impact to lack of epidemiological value. RT-PCR had proofed as time consumable SARS-CoV-2 testing with RT-PCR technology. Most of long time contributed by idle time between pre-analytic to analytic and postanalytic. In this study SARS-CoV-2 testing with RT-PCR had proofed as time consumable Covid-19 testing. Most of long time contributed by idle time between pre-analytic to analytic and post-analytic. It should perform study to deeply investigate the idle time between processes.
\end{abstract}

Keywords: RT-PCR, Covid-19, Patient experience, Quality management

\section{INTRODUCTION}

Weekly analysis held by Indonesia Task Force for Covid-19 (ITF Covid-19) Handling at $1^{\text {st }}$ week September 2020 stated the Covid-19 cases significantly increasing $32.9 \%$ for three weeks consecutively. Seventy districts and cities stated in red zone or area with high risk covid-19 infection from 514 or about $14 \%$ [1]. The spreading of SARS-Cov-2 infection in Indonesia showed significance increasing from period of initial case until September 2020. Realtime report obtained from worldometers.info, Indonesia at rank 23 from all of countries in the world with 214.746 cases at 12 September 2020. Meanwhile Indonesia had just 9.559 tests for 1 million peoples or at rank 163 from all of countries [2]. ITF Covid-19 daily report on 12 September 2020 stated 1.5 million people tested by PCR method and 2.6 million test cumulatively [3]. It's counted 18.800 people average test every day from 1-12 September 2020.

Real-Time Polymerase Chain Reaction (RT-PCR) and Computerized Tomography (CT) scan today are well established Covid-19 diagnostics even though they are expensive and off course it's not suitable for the area with scarcity of resources. The only way to reduce the Covid-19 epidemics when effective vaccine and treatments were not established is applying nanobiosensors to identify infected peoples and then regulate the isolation from healthy individuals [4]. RT-PCR still has the some drawback including probability of false negative, the requirement of additional diagnostics such as CT scan, imbalance between demand and supply of PCR reagents and kits, less found in remote area, will not identify the asymptomatic patients who recovered the infection, the requirement of biosafety conditions, and the need for the expensive thermocycler and professional staff to perform the assay and interpret results [5]-[8]. However, RT-PCR cheaper, easier, widely used, and has a short TAT compare to deoxyribonucleic acid (DNA) sequencing technology. Therefore RT-PCR have played key roles in controlling the SARS-CoV-2 further spreading [9] include in Indonesia. Indonesia had 301 health facilities that delivering the RT-PCR test including governmental institution and private services [3]. Greater Jakarta with high rate of Covid19 cases and high density people and resourceslimited actually is not suitable to arrange testing with RT-PCR. However RT-PCR is still the main intervention to detect Covid-19 infected people. However, public initiative and services didn't restrict to TAT attribute only. TAT is the part of public health 
surveillance which pay-attention to a whole process including case detection and result reporting. Covid19 testing should prioritize accessibility, frequency, and sample-to-answer time [10]. This study aims to investigate the patient's complaint related to time consumable SARS-CoV-2 testing with RT-PCR technology. Previous work on investigate Covid-19 testing patient's satisfaction is very limited. Several study particularly examined the impact of Covid-19 pandemic to healthcare patient's satisfaction. This study aims to investigating and capturing the patient's complaint related to the backward of RT-PCR i.e. time consumable compare to point-of-care (POC) test.

\section{METHOD}

A cross-sectional online survey study had been executed to 174 Indonesian participants in August 2020. We adjust participants with inclusion criteria involve once nasopharyngeal swab specimen sampling, and had received the result exceed 1 day since registration process either negative or positive. Data cleaning applied to investigate missing and redundancy data. The 112 participants involved in this study after applied inclusion criteria and data cleaning. We investigated the patient's experience of SARS-CoV-2 testing from registration, specimen sampling, and receive the results. Collected data were analyzed with proportion descriptive analytics to capturing the time-related attribute of testing.

\section{RESULTS}

\subsection{Perception by Characteristics}

Based on collected data, participants who stated time consumable RT-PCR most a half less than 31 years old, tested at government hospital, and most stayed at Greater Jakarta (table 1)

Table 1 Time Consumable Perception by Participants Characteristics $(n=112)$

\begin{tabular}{|l|l|c|c|}
\hline \multicolumn{1}{|c|}{ Characteristics } & \multicolumn{1}{|c|}{ Indicators } & Frequency & Percent \\
\hline Age & $>50$ years & 3 & 2.7 \\
& 41-50 years & 20 & 17.9 \\
& 31-40 years & 42 & 37.5 \\
& < 31 years & 47 & 42.0 \\
\hline Health services & Government hospital & 48 & 42.9 \\
& Private hospital & 22 & 19.6 \\
& Primary health service & 18 & 16.1 \\
& District clinical laboratory & 8 & 7.1 \\
& Private clinical laboratory & 4 & 3.6 \\
& Others & 12 & 10.7 \\
\hline Living stay & Greater Jakarta & 80 & 71.4 \\
& Out of Greater Jakarta & 32 & 28.6 \\
\hline
\end{tabular}

Table 2 Perception to Registration Process $(n=112)$

\begin{tabular}{|l|l|c|c|}
\hline \multicolumn{1}{|c|}{ Characteristics } & \multicolumn{1}{|c|}{ Indicators } & Frequency & Percent \\
\hline Information access & Most easy & 41 & 36.6 \\
& Easy & 64 & 57.1 \\
& Pretty difficult & 5 & 4.5 \\
& Difficult & 2 & 1.2 \\
\hline Access to location & Most easy & 49 & 43.8 \\
& Easy & 60 & 53.6 \\
& Pretty difficult & 3 & 2.7 \\
& Difficult & 0 & 0.0 \\
\hline Covid-19 protocol properly & Most agree & 48 & 42.9 \\
& Agree & 55 & 49.1 \\
& Pretty disagree & 7 & 6.3 \\
& Disagree & 2 & 1.8 \\
\hline Rapidity \& Alacrity & Very fast \& spry & 31 & 27.7 \\
& Fast \& spry & 60 & 53.6 \\
& Pretty slow & 19 & 17.0 \\
& Very slow & 2 & 1.8 \\
\hline Flow process information & Very clear & 26 & 23.2 \\
& Clear & 54 & 48.2 \\
& Pretty clear & 26 & 23.2 \\
& Unclear (not applied) & 6 & 5.4 \\
\hline Waiting room comfort & Very comfort & 9 & 8.0 \\
& Comfort & 44 & 39.3 \\
& Pretty comfort & 18 & 36.6 \\
& Uncomfortable & 37 & 16.1 \\
\hline Queue discipline & Very fair (first in first out) & & 33.0 \\
\hline
\end{tabular}




\begin{tabular}{|l|l|c|c|}
\hline \multicolumn{1}{|c|}{ Characteristics } & \multicolumn{1}{|c|}{ Indicators } & Frequency & Percent \\
\hline & Fair & 21 & 18.8 \\
& Pretty fair & 51 & 45.5 \\
& Unfair & 3 & 2.7 \\
\hline Time consume & $>5$ minutes & 34 & 30.4 \\
& $3-5$ minutes & 34 & 30.4 \\
& $1-3$ minutes & 36 & 32.1 \\
& $<1$ minutes & 8 & 7.1 \\
\hline Satisfaction & Very satisfy & 58 & 16.1 \\
& Satisfy & 36 & 51.8 \\
& Pretty satisfy & 0 & 32.1 \\
& Unsatisfied & & 0.0 \\
\hline
\end{tabular}

Table 3 Perception to Swab Sampling Process $(n=112)$

\begin{tabular}{|l|l|c|c|}
\hline \multicolumn{1}{|c|}{ Characteristics } & Indicators & Frequency & Percent \\
\hline Distance from registration counter & Far & 10 & 8.9 \\
& Middle & 39 & 34.8 \\
& Close & 63 & 56.3 \\
\hline Queue discipline & Very fair (first in first out) & 28 & 25.0 \\
& Fair & 55 & 49.1 \\
& Pretty fair & 25 & 22.3 \\
& Unfair & 4 & 3.6 \\
\hline Waiting room comfort \& safety & Very comfort \& safety & 7 & 6.3 \\
& Comfort \& safety & 48 & 42.9 \\
& Pretty comfort \& safety & 40 & 35.7 \\
& Uncomfortable \& unsafe & 17 & 15.2 \\
\hline Flow process information & Very clear & 23 & 20.5 \\
& Clear & 61 & 54.5 \\
& Pretty clear & 23 & 20.5 \\
& Unclear (not applied) & 5 & 4.5 \\
\hline Flow process information & Very clear & 26 & 23.2 \\
& Clear & 54 & 48.2 \\
& Pretty clear & 26 & 23.2 \\
& Unclear (not applied) & 6 & 5.4 \\
\hline Pain perception & Very pain & 4 & 3.0 \\
& Pain & 32 & 28.6 \\
& Pretty pain & 47 & 42.0 \\
& Painless & 29 & 25.9 \\
\hline Time consume & S minutes & 3 & 2.7 \\
& $3-5$ minutes & 57 & 20.5 \\
& $1-3$ minutes & 31 & 49.1 \\
& L1 minutes & 27.7 \\
\hline & Very satisfy & 5 & 10.7 \\
& Satisfy & 59.8 \\
& Pretty satisfy & 25.0 \\
& Unsatisfied & 4.5 \\
\hline
\end{tabular}

Table 4. Perception to All Process $(n=112)$

\begin{tabular}{|c|l|c|c|}
\hline Characteristics & \multicolumn{1}{|c|}{ Indicators } & Frequency & Percent \\
\hline Satisfaction & Very satisfy & 10 & 8.9 \\
& Satisfy & 60 & 53.6 \\
& Pretty satisfy & 36 & 32.1 \\
& Unsatisfied & 6 & 5.4 \\
\hline
\end{tabular}

\subsection{Perception to registration process}

From 112 participants, $41 \%$ stated the waiting room pretty comfort, $45.5 \%$ stated pretty unfair when waiting in line, $60 \%$ stated need exceed to 3 minutes for registration process (table 2).

\subsection{Perception to swab sampling process}

From 112 participants, $42 \%$ stated pretty pain when swab sampling, and $49.1 \%$ stated need 1-3 minutes for swab sampling process (table 3 ).

\subsection{Perception to All Process}

Even though most of participants need over 1 day to receive results, 54\% stated satisfy for the RT-PCR services (table 4 ) 


\section{DISCUSSION}

Participants who stated long RT-PCR service time mostly had tested in government hospital and at Greater Jakarta. This means that RT-PCR test demand concentrate to public health services according to Covid-19 policy. The increasing Covid-19 cases in Greater Jakarta led to longer service time. Result of RT-PCR test focused to people with high risk ( $>45$ years) that led to longer service time to people less than 31 years.

Several health services applied Covid-19 protocol that separate patients with people who held RT-PCR. Most of all health services arrange RT-PCR at out of building (field, parking, park) that led to the uncomfortable for waiting the registration process. Health worker adjusted priority queue with people with high risk as first class patients. As a result, most of participant perceipt unfair waiting line for registration process.

Specimen for RT-PCR swab from nasoparhyngeal and parhyngeal tissue. This procedure led to the uncomfortable sampling even painfull for several person. However, this service attribute along to our observation had no effect to long service time. Moreover, most of participants stated this process need less time.

In the early stages of pandemics, precise and accurate diagnosis had significance contribution to control the transmission of diseases. In order to diagnosis SARS, the time consumable and sophisticated laboratory with trained personal are to be required [4]. In this study 28/58 (48.3\%) participants stated time spending from registration to receiving results exceed to 3 days in government hospital. We suggest the root causal of this condition is the idle time of waiting in line the speciment before turn-around time.

Testing time of real-time RT-PCR is $1.5-3$ hours [7]. United Kingdom National Health Service (NHS) laboratory reported average TAT of Covid-19 PCR testing is 14 hours, and $90 \%$ under 24 hours on June 2020. TAT is time interval between the specimens received in the laboratory reception to the time of report dispatched with verification [11].

Qualitative study held by [12] suggest that RT-PCR test at Off-Site Covid-19 Testing Centres (OSCTC) need variability sample processing and TAT from days to weeks. Indeed, OSCTs needed to retest patients to support contact tracing if there is significance delay cases. Daily telemedicine visits with patients until they receive result is one of way outs to solve the time consumable problem. If the result is negative, the additional $48 \mathrm{hrs}$ follow-up should arrange to make sure a false negative.

The delay time of RT-PCR would make matter worse to Covid-19 pandemics. Surveillance model simulation study suggests that delay in reporting Covid-19 decrease the epidemiological impact of surveillance-driven isolation. Delay reporting will decrease reproductive number $(\mathrm{R})$ only about $60 \%$ if surveillance held daily. When surveillance every 14 days, it will decrease R about $10-15 \%$ only [10].

\section{CONCLUSION}

In this study SARS-CoV-2 testing with RT-PCR had proofed as time consumable Covid-19 testing. Most of long time contributed by idle time between preanalytic to analytic and post-analytic. Perception of long service time related to age, health facilities, and area. It should perform study to deeply investigate the idle time between processes.

\section{REFERENCES}

[1] Satgas Penangangan Covid-19 BNPB, "ANALISIS DATA COVID-19 INDONESIA UPDATE PER 06 SEPTEMBER 2020," Jakarta, 2020.

[2] Worldometer, "Coronavirus Cases," Worldometer, 2020.

https://www.worldometers.info/coronavirus/? (accessed Jul. 31, 2020).

[3] Gugus Tugas Percepatan Penanganan COVID-19, "Infografis COVID-19 (12 September 2020)," Berita Terkini Covid-19, 2020.

https://covid19.go.id/p/berita/infografiscovid-19-12-september-2020 (accessed Sep. 13, 2020).

[4] M. Ezhilan, I. Suresh, and N. Nesakumar, "SARS-CoV, MERS-CoV and SARS-CoV-2: A Diagnostic Challenge," Meas. J. Int. Meas. Confed., vol. 168, no. August 2020, p. 108335, 2021, doi: 10.1016/j.measurement.2020.108335.

[5] H. Moulahoum, F. Ghorbanizamani, F Zihnioglu, K. Turhan, and S. Timur, "How should diagnostic kits development adapt quickly in COVID 19-like pandemic models? Pros and cons of sensory platforms used in COVID-19 sensing," Talanta, vol. 222, no. July 2020, p. 121534, 2021, doi: 10.1016/j.talanta.2020.121534.

[6] E. Sheikhzadeh, S. Eissa, A. Ismail, and M. Zourob, "Diagnostic techniques for COVID19 and new developments," Talanta, vol. 220, no. May, p. 121392, 2020, doi: 10.1016/j.talanta.2020.121392.

[7] Y. Xu, M. Cheng, X. Chen, and J. Zhu, "Current approach in laboratory testing for SARS-CoV-2,” Int. J. Infect. Dis., 2020, doi: 10.1016/j.ijid.2020.08.041.

[8] J. M. Abduljalil, "Laboratory diagnosis of SARS-CoV-2: available approaches and limitations," New Microbes New Infect., vol. 36, no. June, p. 100713, 2020, doi: 10.1016/j.nmni.2020.100713.

[9] J. W. Ai, Y. Zhang, H. C. Zhang, T. Xu, and W. H. Zhang, "Era of molecular diagnosis for pathogen identification of unexplained pneumonia, lessons to be learned," Emerg. Microbes Infect., vol. 9, no. 1, pp. 597-600, 2020, doi: 10.1080/22221751.2020.1738905.

[10] D. B. Larremore et al., "Test sensitivity is secondary to frequency and turnaround time for COVID-19 surveillance," medRxiv, p. 
2020.06.22.20136309, 2020, doi: 10.1101/2020.06.22.20136309.

[11] NHS United Kingdom, "Pillar 1 NHS labs Covid-19 testing turnaround time data The current average Covid-19 testing turnaround time in the NHS pathol."

https://webcache.googleusercontent.com/sear ch?q=cache:2URQJw23YvAJ:https://www.en gland.nhs.uk/coronavirus/wpcontent/uploads/sites/52/2020/07/nhs-labs- covid-19-testing-turnaround-timedata.pdf $+\& \mathrm{~cd}=1 \& \mathrm{hl}=\mathrm{en} \& \mathrm{ct}=\mathrm{clnk} \& \mathrm{gl}=\mathrm{id}$ (accessed Sep. 08, 2020).

[12] C. Brammer et al., "Qualitative review of early experiences of off-site COVID-19 testing centers and associated considerations," Healthcare, vol. 8, no. 3, p. 100449, 2020, doi:

10.1016/j.hjdsi.2020.100449. 